\title{
Effect of transient thermal shocks on alcoholic fermentation performance
}

\author{
A.S. Vargas-Trinidad ${ }^{\mathrm{a}, \mathrm{b}, 1}$, M.C. Lerena ${ }^{\mathrm{a}, \mathrm{b}, 1}$, J. Alonso-del-Real ${ }^{\mathrm{c}}$, B. Esteve-Zarzoso ${ }^{\mathrm{d}}$, L.A. Mercado ${ }^{\mathrm{a}}$, \\ A. Mas ${ }^{\mathrm{d}}$, A. Querol ${ }^{\mathrm{c}}$, M. Combina ${ }^{\mathrm{a}, \mathrm{b}, *}$ \\ ${ }^{a}$ Estación Experimental Agropecuaria Mendoza, Instituto Nacional de Tecnología Agropecuaria (INTA), San Martín 3853 (5507) Luján de Cuyo, Mendoza, Argentina \\ ${ }^{\text {b }}$ Consejo Nacional de Investigaciones Científicas y Tecnológicas (CONICET), Argentina \\ ${ }^{\mathrm{c}}$ Departamento de Biotecnología de los Alimentos, Grupo de Biología de Sistemas en Levaduras de Interés Biotecnológico, Instituto de Agroquímica y Tecnología de los \\ Alimentos (IATA)-CSIC, Valencia, Spain \\ ${ }^{\mathrm{d}}$ Departament de Bioquímica i Biotecnologia, Facultat d'Enologia, Universitat Rovira i Virgili, Tarragona, Spain
}

\section{A R T I C L E I N F O}

\section{Keywords:}

Wine

Sluggish fermentations

Heat shock

Nitrogen addition

\begin{abstract}
A B S T R A C T
Stuck and sluggish fermentations are among the main problems in winemaking industry leading to important economic losses. Several factors have been described as causes of stuck and sluggish fermentations, being exposure to extreme temperatures barely studied. The objective of this study was to identify thermal conditions leading to stuck and sluggish fermentations, focusing on the impact of an abrupt and transient decrease/increase of temperature on fermentation performance and yeast viability/vitality. Different strains of Saccharomyces cerevisiae, SBB11, T73, and PDM were evaluated in synthetic grape must fermentations. Cold shocks $\left(9^{\circ} \mathrm{C}\right.$ and $1.5^{\circ} \mathrm{C}$ for $16 \mathrm{~h}$ ) carried out on different days during the fermentation process were unable to alter fermentation performance. Conversely, shock temperatures higher than $32{ }^{\circ} \mathrm{C}$, applied in early stages of the process, lead to sluggish fermentation showing a delay directly related to the temperature increase. Fermentation delay was associated with a decrease in cell vitality. The impact of the heat shock on fermentation performance was different depending on the strain evaluated and nitrogen supplementation (with or without diammonium phosphate addition). None of the conditions evaluated produced a stuck fermentation and importantly, in all cases must nutrition improved fermentation performance after a heat shock.
\end{abstract}

\section{Introduction}

Wine fermentation is probably one of the most ancient biotechnological processes carried out by microorganisms ever described (Samuel, 1996). During fermentation, sugars present in grape must, mainly glucose and fructose, are converted into ethanol and carbon dioxide mainly by the yeast Saccharomyces cerevisiae (Ribereau-Gayon et al., 2006).

Despite many advances have been done in the field of wine fermentation technology, stuck or sluggish fermentations remain an important problem faced annually by oenologist and winemakers all over the world (Bisson, 1999, Maisonnave et al., 2013, Malherbe et al., 2007). A fermentation is considered stuck or sluggish when sugar consumption stops or when its rate is too low for practical purposes (Bisson, 1999). When fermentation stops early, high residual sugar in the wines makes them microbiologically unstable and more susceptible to spoilage, with possible losses of quality and wine value (Lonvaud-
Funel, 1999; Maisonnave et al., 2013). Restarting stuck or sluggish fermentations challenges winemakers because, even when restarting procedures succeed and fermentation finishes, wine quality is often affected (Urtubia et al., 2012). Therefore, it is important to detect and identify the factors that could lead to problematic fermentations.

Many possible causes of problematic fermentation have been described, such as nutrient limitation, toxicity of agricultural residues present in grapes (fungicides, pesticides), grape sanity and extreme temperatures, among others (Malherbe et al., 2007). All these factors suppose stress conditions that could have an adverse effect on growth or viability/vitality of yeast cells leading to alterations in sugar rate consumption and hence a problematic fermentation (Ivorra et al., 1999; Malherbe et al., 2007). Thermal shocks (transient and abrupt increases or decreases in temperature) have been barely studied as causes of stuck or sluggish fermentations (Malherbe et al., 2007; Valentine et al., 2018). On one hand, we have observed in our Experimental Winery that sudden drops in temperature, often occurring during the first days of

\footnotetext{
* Corresponding author at: Estación Experimental Agropecuaria Mendoza, Instituto Nacional de Tecnología Agropecuaria (EEA Mza INTA), San Martín 3853 , 5507 Luján de Cuyo, Mendoza, Argentina.

E-mail address: combina.mariana@inta.gob.ar (M. Combina).

${ }^{1}$ Equal contribution.
} 


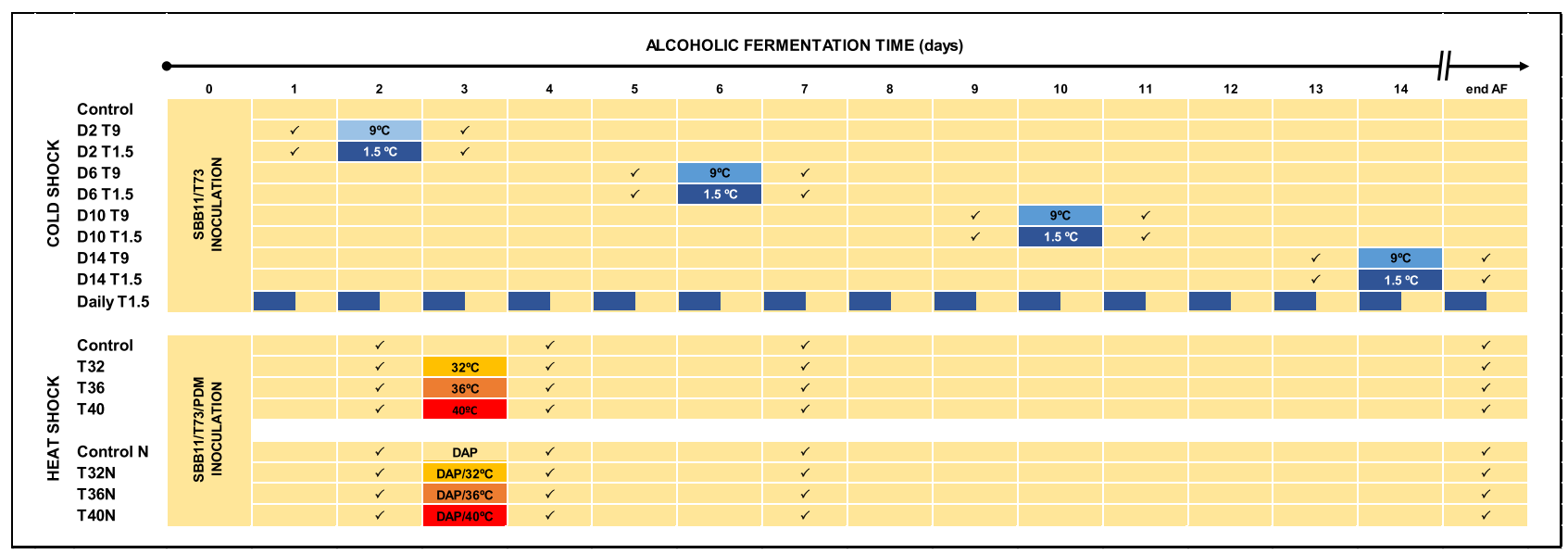

Fig. 1. Schematic experimental design of the assay. Each treatment was carried out in independent triplicates for each yeast strain. Alcoholic fermentation was conducted at $26^{\circ} \mathrm{C}$. Thermal shocks are represented in different colours and were applied for $16 \mathrm{~h}$. DAP: diammonium phosphate supplementation. $\checkmark$ : flow cytometry analysis. (For interpretation of the references to color in this figure legend, the reader is referred to the web version of this article.)

autumn, occasionally produce problems in fermentation development of late harvest grapes. The synergy of a cold shock with others stressors such as high ethanol content and starved cells (by the end of alcoholic fermentation) has not been studied before. On the other hand, increasing initial grape must temperatures have been reported (Coulter et al., 2008). In the grape-growing regions with warm and very warm climate (heliothermal index: $\mathrm{HI}+2$ and $\mathrm{HI}+3$ ) (Tonietto and Carbonneau, 2004) the high environmental temperature during harvest could affect winemaking in different ways. For instance, harvest of grapes berries during hot days favours an increase in initial must temperature. Additionally, grape temperature can increase even more due to the waiting time of the trucks until the discharge into the cellar, as it has been frequently observed in large volume wineries (Coulter et al., 2008). To this regard, the use of stainless steel tanks with thermal regulation aims to overcome these issues in the industrial wineries. Although there are still many "garage" and/or large volume wineries that use other materials such as concrete tanks for fermentations with deficient thermal control (Coulter et al., 2008).

Increases in temperature also occur due to the fermentation process itself. Grape must temperature increases at a rate of $1.3{ }^{\circ} \mathrm{C}$ for every $100 \mathrm{~g}$ of sugars consumed during fermentation due to the heat produced by yeast metabolism (Bisson et al., 2007). Therefore, temperature increases around $12{ }^{\circ} \mathrm{C}$ to $15^{\circ} \mathrm{C}$ can occur and consequently grape must temperature can reach more than $40^{\circ} \mathrm{C}$ (Schmid et al., 2009, Valentine et al., 2018). Additionally, red grape fermentation is conducted together with their skins that form the cap on top of the liquid (Schmid et al., 2009). In this way, heat is not uniformly distributed and the highest temperatures occur in the cap (Bisson et al., 2007; Guerrini et al., 2017; Schmid et al., 2009; Valentine et al., 2018). The addition of nitrogen during vinification has a direct impact on yeast metabolic activity, which may as well favour temperature increases (Bisson, 1999; Malherbe et al., 2007). Nitrogen supplementation during the first half of the fermentation (must density of $1060 \mathrm{mg} / \mathrm{L}$ ) is a widely used oenological practice since it enhances the kinetics and reduces fermentation length (Beltran et al., 2005).

The aim of this study was to identify thermal conditions leading to sluggish or stuck fermentations, focusing on the impact of a transient and abrupt increase/decrease of temperature (thermal shock) on fermentation performance and viability/vitality of yeas56ts during alcoholic fermentation.

\section{Material and methods}

\subsection{Yeast strains and inoculum preparation}

Three strains of Saccharomyces cerevisiae were tested in this study: SBB11, T73 and PDM. Strain SBB11 is a native $S$. cerevisiae strain selected for red wine fermentation isolated from Syrah grapes from Mendoza, Argentina, whereas T73 and PDM are commercial strains from Lallemand and Maurivin Companies respectively. Yeast cells were plated and grown on Yeast Peptone Dextrose (YPD) medium. Single colonies were spread into five YPD plates and incubated for $48 \mathrm{~h}$ at $28^{\circ} \mathrm{C}$ in order to get confluent growth. Yeasts were collected in $100 \mathrm{~mL}$ YPD broth and incubated with agitation at $150 \mathrm{rpm}$ for $6 \mathrm{~h}$ at $28^{\circ} \mathrm{C}$. To determine the dilution for inoculation in synthetic grape must in order to obtain an initial cell concentration of $2 \times 10^{6}$ cells $/ \mathrm{mL}$, cells were counted in Neubauer chamber. Synthetic grape must (SM) was prepared with $120 \mathrm{~g} / \mathrm{L}$ glucose and $120 \mathrm{~g} / \mathrm{L}$ fructose (Bely et al., 1990). Nitrogen content adjusted to $140 \mathrm{mg} \mathrm{N} / \mathrm{L}$ ( $42 \mathrm{mg} \mathrm{N} / \mathrm{L}$ as ammonium and $98 \mathrm{mg}$ N/L in amino acid form) and $\mathrm{pH}$ to 3.3 with $\mathrm{NaOH}$. Finally, SM was sterilized through filtration by $0.2 \mu \mathrm{m}$ membrane.

\subsection{Microvinifications}

Fermentations were performed in $500 \mathrm{~mL}$ Erlenmeyer flasks equipped with Müller valves containing $300 \mathrm{~mL}$ of $\mathrm{SM}$ at $26^{\circ} \mathrm{C} \pm 2{ }^{\circ} \mathrm{C}$ with a daily manual shaking in order to simulate pumping over normally performed at industrial winemaking. Weight loss and must density were daily monitored for cold shock and heat shock assays respectively. Fermentation was considered to be finished when residual sugar concentration was below $4 \mathrm{~g} / \mathrm{L}$ (Bisson, 1999). Must density was measured by densitometer (Densito 30 PX, Mettler Toledo, Switzerland). Residual sugar concentration was measured by a glucose/fructose enzymatic test (Roche, Darmstadt, Germany) at the end of each assay.

\subsection{Experimental design}

Different experimental approaches were designed in order to mimic the thermal changes that may occur during wine fermentation. Regarding cold shock assays, the impact of a single cold shock applied on different moments of alcoholic fermentation was studied. Abrupt decreases of $9{ }^{\circ} \mathrm{C} \pm 2{ }^{\circ} \mathrm{C}$ (T9) and $1.5^{\circ} \mathrm{C} \pm 2{ }^{\circ} \mathrm{C}$ (T1.5) for $16 \mathrm{~h}$ were applied independently on day 2, 6, 10 and 14 days after initiation of alcoholic fermentation (Fig. 1). Also, a daily cold shock assay was included, by placing flasks at $1.5 \pm 2{ }^{\circ} \mathrm{C}$ (Daily 1.5) in a cold chamber 


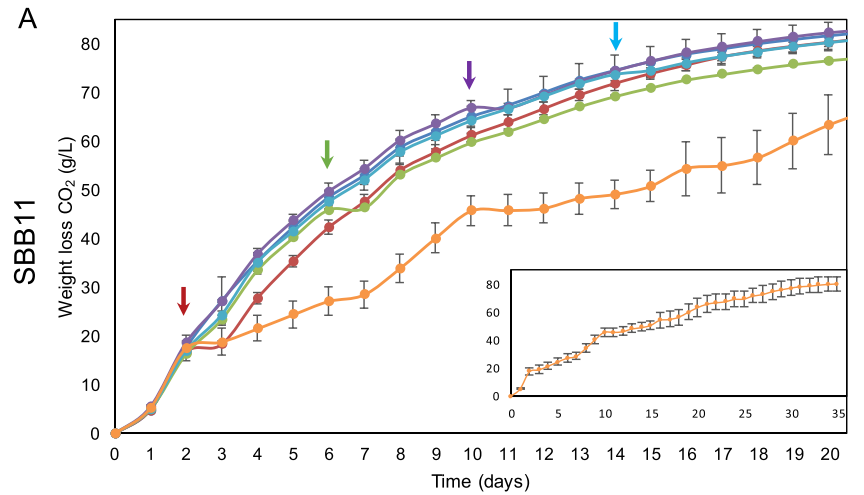

B

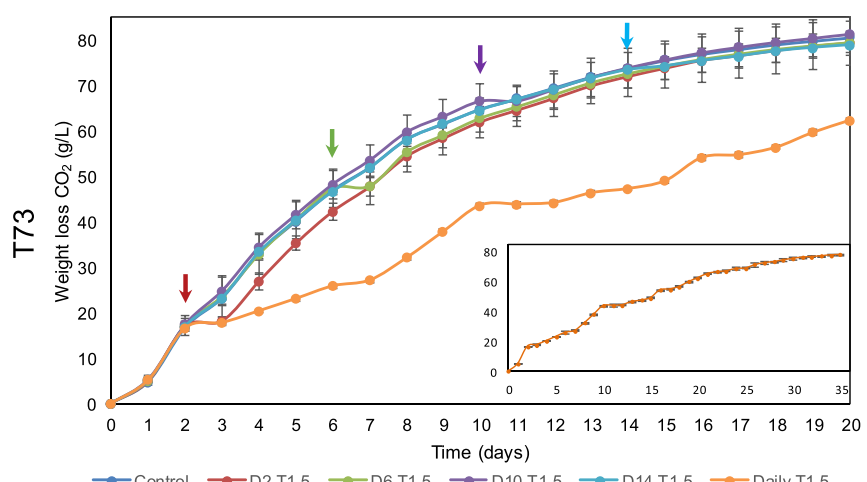

Fig. 2. Effect of cold shock on fermentation performance of two yeast strains: SBB11 (A) and T73 (B). Fermentations were conducted at $26^{\circ} \mathrm{C}$ and cold shocks applied for $16 \mathrm{~h}$ on different days are indicated by arrows. Fermentation progress was monitored as cumulative mass loss $\left(\mathrm{CO}_{2} \mathrm{~g} / \mathrm{L}\right)$. Insets show the complete fermentation profile for the treatment "Daily T $1.5^{\circ} \mathrm{C}$ ". The data represent the average of triplicate \pm SD.

overnight, in order to produce periodic cold shocks in the same fermentation trial. Every cold shock trial was performed for two yeast strains (SBB11 and T73) in triplicates and control treatment was carried out at constant temperature $\left(26 \pm 2{ }^{\circ} \mathrm{C}\right)$ (Fig. 1).

Regarding heat shock assays, the impact of three different temperatures increases applied on early stage of fermentation was studied. Abrupt increases of $32{ }^{\circ} \mathrm{C} \pm 2{ }^{\circ} \mathrm{C}$ (T32); $36^{\circ} \mathrm{C} \pm 2{ }^{\circ} \mathrm{C}$ (T36) and $40^{\circ} \mathrm{C} \pm 2{ }^{\circ} \mathrm{C}(\mathrm{T} 40)$ for $16 \mathrm{~h}$ were applied on day 3 of fermentation (must density $1060 \pm 5 \mathrm{mg} / \mathrm{L}$ ) by placing flasks in incubators set to the different temperatures. Additionally, fermentations were carried out with or without nitrogen supplementation. Three hours before the heat shock, $200 \mathrm{mg} / \mathrm{L}$ of diammonium phosphate (DAP) was added in the nitrogen supplemented treatments (Fig. 1). Internal temperature of each treatment was monitored with sensors (iButton ${ }^{\circledast}$ ) placed inside the Erlenmeyer flasks.

\subsection{Yeast viability and vitality determination by flow cytometry}

Cell viability and vitality were determined by flow cytometry using a commercial kit (Fungal Light ${ }^{\mathrm{TM}}$ CFDA,AM/Propidium Iodide Yeast Vitality Kit, Molecular Probes ${ }^{\mathrm{TM}}$, USA). Cell viability was assessed by staining with propidium iodide (PI). Cell vitality was assessed by staining with acetoxymethyl ester of 5-carboxyfluorescein diacetate (CFDA,AM) which can permeate the membrane and become fluorescent inside metabolically active cells. Stained cells were analysed using a C6 cytometer (Accuri, BD Biosciences, California, USA) and fluorescence images were acquired and processed with the software (BD CSampler). Fluorescence measurements were collected in FL1 $(530 / 30 \mathrm{~nm}$ BP filter) to determine cells stained with CFDA,AM; whereas PI stained cells were collected in FL3 ( $>670 \mathrm{~nm}$ LP filter). Gates corresponding to viable/non-viable cells were previously set using control of viable cells (from control conditions) or non-viable cells (heat-killed cells treated at $90^{\circ} \mathrm{C}$ for $10 \mathrm{~min}$ ). Yeast cells from each fermentation were suspended in phosphate buffered saline (PBS) and diluted to a final concentration of $1 \times 10^{6}$ cells $/ \mathrm{mL}$. One $\mathrm{mL}$ of cell dilution was stained at $37^{\circ} \mathrm{C}$ for 15 min with PI and CFDA,AM according to supplier recommendations. According to cell staining, three different yeast populations were defined: (1) CFDA + PI-, vital and viable cells, (2) CFDA + PI +, vital cells with damaged membrane and (3) CFDA- PI+, non-vital non-viable cells. Random samples were also analysed by plating on YPD media in order to validate and compare both methods for viability determination. Results were expressed as vitality reduction, normalizing data with its respective control as described below:

Vitality reduction $(\%)=100-\frac{\left(\mathrm{CFDA}+_{\text {heat shock }} * 100\right)}{\mathrm{CFDA}+_{\text {control }}}$

\subsection{Statistical analyses}

The overall fermentation performance of the different trials was statistically analysed estimating the area under the curve in the density vs. time graph (AUC). This parameter was calculated using Riemann sum area under the curve (AUC) method from inoculation time until day 11 , and results are expressed as arbitrary units. Day 11 was chosen to compare all treatments according to the shortest fermentation length. All analyses were carried out with statistical software (Infostat, FCA, Universidad Nacional de Córdoba, Argentina). The AUC data were statistically analysed using two-way ANOVA and comparisons were performed with LSD Fisher test $(p \leq 0.05)$.

\section{Results}

The transient and abrupt decrease in temperature (cold shock) did not affect the fermentation in any of the treatments evaluated in both strains studied (SBB11 and T73) compared to the control condition. Alcoholic fermentation had the same length in all the cases, suggesting that an abrupt decrease of $17^{\circ} \mathrm{C}$ (from $26^{\circ} \mathrm{C}$ to $9^{\circ} \mathrm{C}$ ) was not able to affect the global performance of alcoholic fermentation, regardless the day the cold shock was applied. Furthermore, we reduced the temperature more drastically (from $26^{\circ} \mathrm{C}$ to $1.5^{\circ} \mathrm{C}$ ) for $16 \mathrm{~h}$ using the same approach previously described. Again, no effect was observed on general alcoholic fermentation performance in any of the cases studied. A slight but momentary arrest on fermentation rate was observed immediately after the cold shock, however regular rate was recovered straightaway once placing back the flasks at $26^{\circ} \mathrm{C}$ (Fig. 2). In order to mimic environmental temperature variations (warm days and cold nights) we designed a third approach where cold socks $\left(1.5^{\circ} \mathrm{C}\right)$ were daily applied. Fermentation rate showed to be clearly slower than the control, as expected. However, fermentation continued and finished consuming all sugars by day 35 (Fig. 2). Thus, cold shock did not produce any stuck fermentation. Also, yeast viability/vitality was determined by flow cytometry and no difference was observed for any of the conditions assessed in comparison with the control (data not shown).

To study transient and abrupt increase in temperature (heat shock) as a possible cause of stuck or sluggish fermentations, synthetic must inoculated with three different $S$. cerevisiae strains (SBB11, T73 and PDM) was subjected to an abrupt upshift on temperature $\left(32^{\circ} \mathrm{C}, 36^{\circ} \mathrm{C}\right.$ and $40^{\circ} \mathrm{C}$ ) for $16 \mathrm{~h}$ on day 3 of the fermentation process (Fig. 3). These assays were performed in the presence or absence of DAP supplementation. Regarding the heat shock at $32{ }^{\circ} \mathrm{C}$, no differences were observed in the fermentation performance for all the studied strains compared to their respective controls. This small increase in temperature $\left(6^{\circ} \mathrm{C}\right.$, from $26^{\circ} \mathrm{C}$ to $\left.32^{\circ} \mathrm{C}\right)$ in the early stages of fermentation was not able to affect yeast viability/vitality, regardless DAP supplementation (data not shown). In contrast, heat shock at higher 


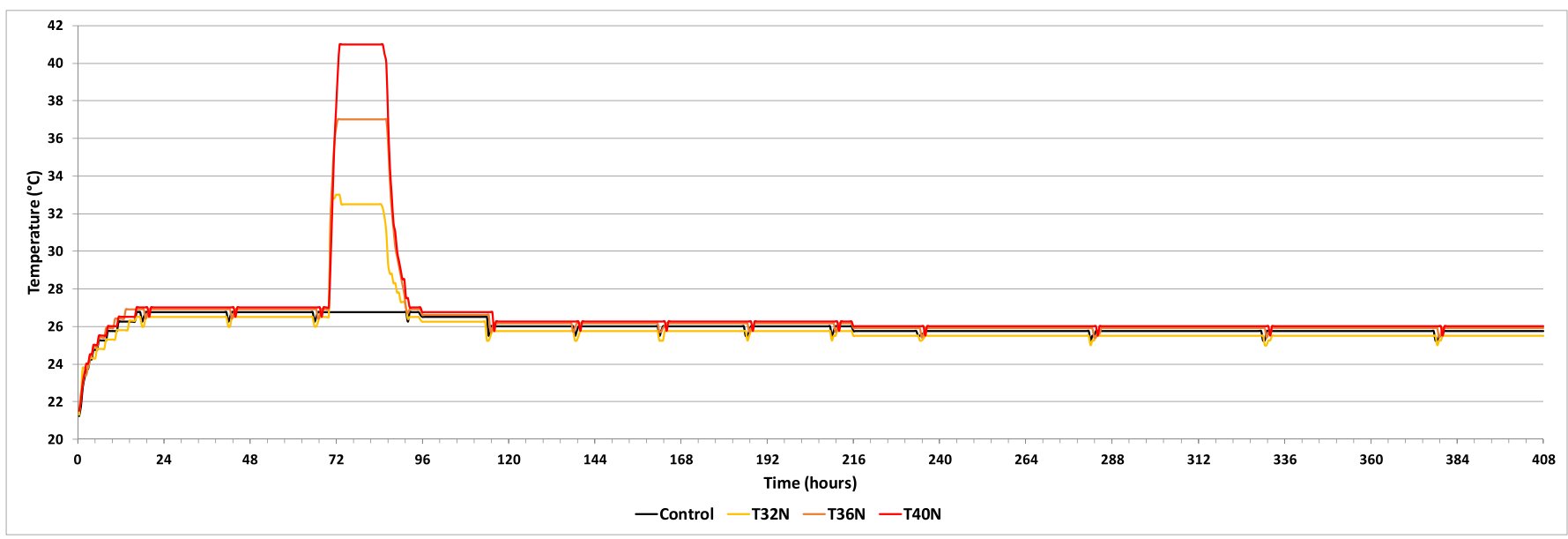

Fig. 3. Internal temperature profile during heat shock assay, recorded with sensors (iButton ${ }^{\circledast}$ ). Fermentations were carried out with DAP supplementation at $26^{\circ} \mathrm{C}$. Thermal shocks $\left(32{ }^{\circ} \mathrm{C}, 36^{\circ} \mathrm{C}\right.$ and $\left.40^{\circ} \mathrm{C}\right)$ were applied for $16 \mathrm{~h}$.

A

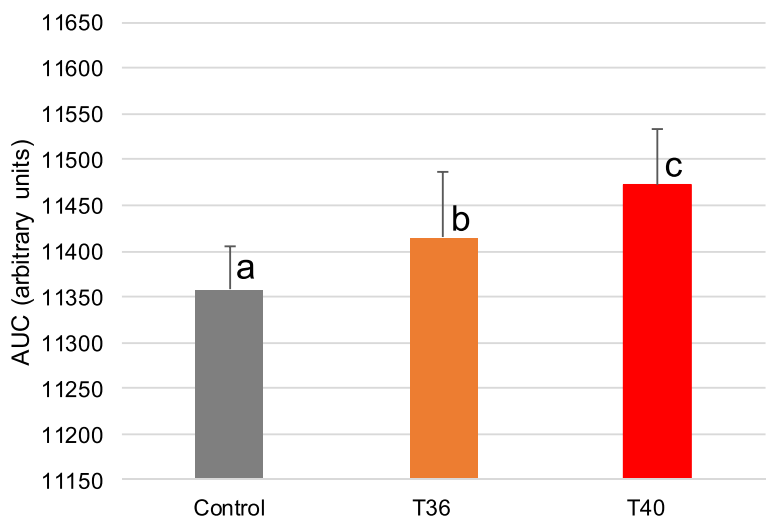

B

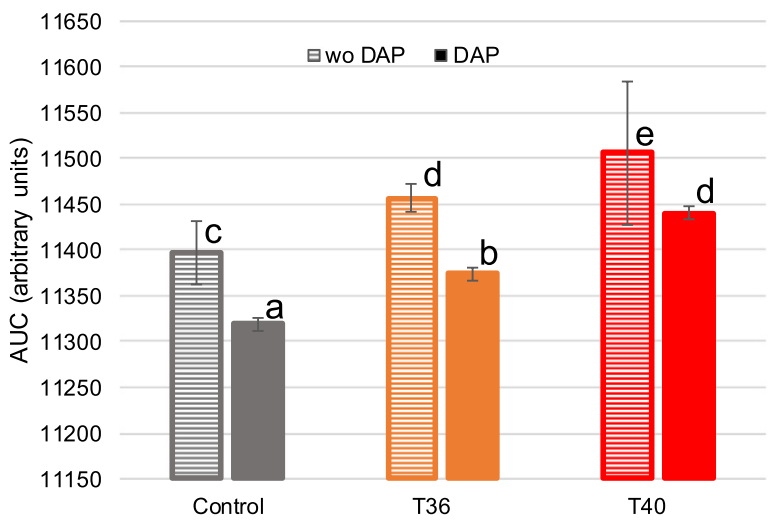

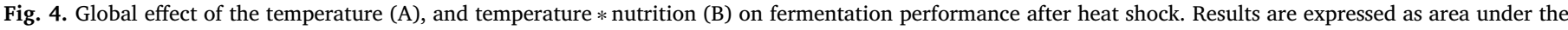

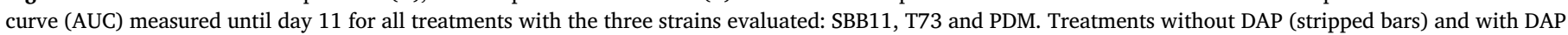
supplementation (filled bars). Different letters mean statistical differences between the treatments (LSD Fisher test $p<0.05$ ).

temperatures $\left(36^{\circ} \mathrm{C}\right.$ and $\left.40^{\circ} \mathrm{C}\right)$ did show an effect on alcoholic fermentation performance. Fig. 4 shows the effect of heat shocks on fermentation performance expressed as AUC, where higher AUC values represents a stronger reduction in fermentation rate. Fig. 4 also shows in which way this effect was modified in the presence of DAP supplementation. As expected higher temperatures produced a stronger reduction on fermentation rate, yielding higher AUC (Fig. 4A). Interestingly, DAP supplementation was able to reduce the negative effect on fermentation performance when heat shocks were applied (Fig. 4B).

Each strain showed different responses to heat shocks and consequently different global fermentation performance (Fig. 5). These observations may be associated to the specific characteristics of each strain, such as its thermotolerance and nitrogen requirements. In the case of SBB11, the thermal shocks of $36^{\circ} \mathrm{C}$ and $40{ }^{\circ} \mathrm{C}$ led to sluggish fermentations in both nutritional conditions (Fig. 5AB). A delay of 18 and 20 days on the fermentation length respect to the control was observed for $36^{\circ} \mathrm{C}$ and $40^{\circ} \mathrm{C}$ heat shock treatments respectively, in must without DAP supplementation (Fig. 5A). Likewise, a delay on fermentation length of 11 and 26 days respect to the control condition was observed in DAP supplemented musts after heat shocks at $36^{\circ} \mathrm{C}$ and $40^{\circ} \mathrm{C}$ respectively (Fig. 5B). DAP supplementation reduced AUC in all treatments assessed with this strain (Fig. $5 \mathrm{C}$ ). More than 40 days were necessary to finish alcoholic fermentation when a $40{ }^{\circ} \mathrm{C}$ heat shock was applied, in both nutritional conditions (Fig. 5AB). Regarding T73, heat shock treatments led to a clear sluggish fermentation, being more intense in the absence of DAP supplementation (Fig. 5DE). In $40^{\circ} \mathrm{C}$ heat shock treatments, twice as much time was needed to consume all the sugars compared to the control in both nutritional conditions. A clear effect of nutrition was observed for this strain. DAP supplementation was able to moderate the impact of a heat shock at $40^{\circ} \mathrm{C}$ and $36^{\circ} \mathrm{C}$, bringing similar AUC to that of the control without nutrition (Fig. 5F). Finally, in the case of PDM a clear sluggish fermentation was observed after a $40^{\circ} \mathrm{C}$ heat shock treatment regardless DAP supplementation; whereas no differences were observed in the AUC for $36^{\circ} \mathrm{C}$ heat shock treatments (Fig. 5GI). Even when DAP supplementation in $40^{\circ} \mathrm{C}$ treatments did not moderate the impact of heat shock on AUC measurements, total fermentation length was clearly reduced when musts were supplemented with DAP, suggesting that a possible fermentation reactivation after day 11 could be favoured by nutrition (Fig. 5GH).

The percentage of viable/vital yeasts was higher than $98 \%$ in all samples analysed before the heat shock. The day after the heat shock (day 4) yeast viability/vitality was determined. The percentages of vitality in the fermentations subjected to thermal shock at $32{ }^{\circ} \mathrm{C}$ did not show differences with their respective control, suggesting no effect on yeast vitality (data not shown). Conversely, at $36^{\circ} \mathrm{C}$ and $40{ }^{\circ} \mathrm{C}$ the percentages of vital cells with damaged membranes (CFDA + PI+) were negligible compared to the other populations (CFDA + PI- and CFDA- PI-). Therefore, in further analyses vital cells were quantified including all CFDA + stained cells, regardless membrane integrity (PIand PI+). In Fig. 6, the effect of heat shock on cells vitality the day 
A
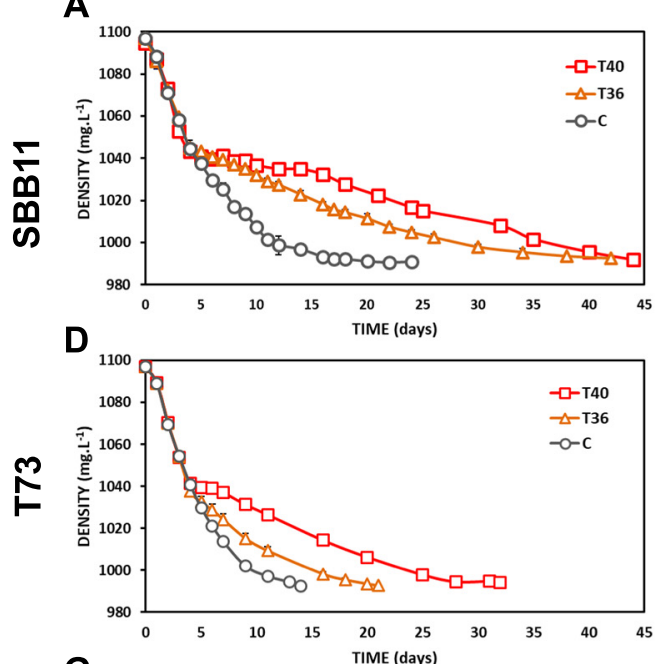

G

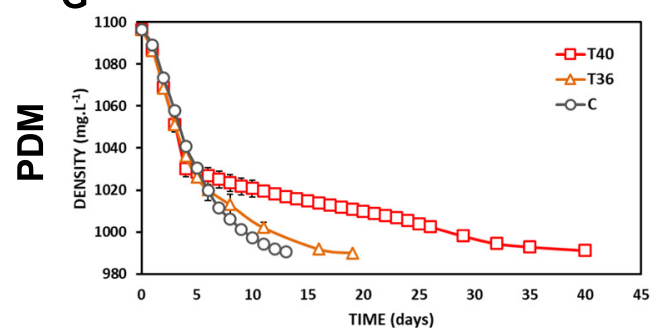

B

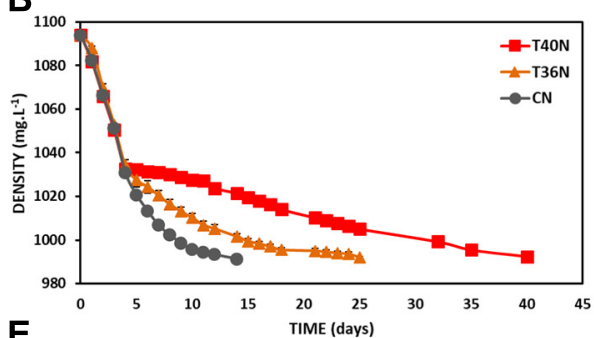

$E_{1}$

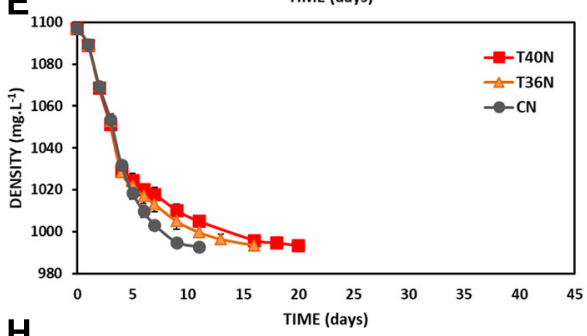

$\mathbf{H}$

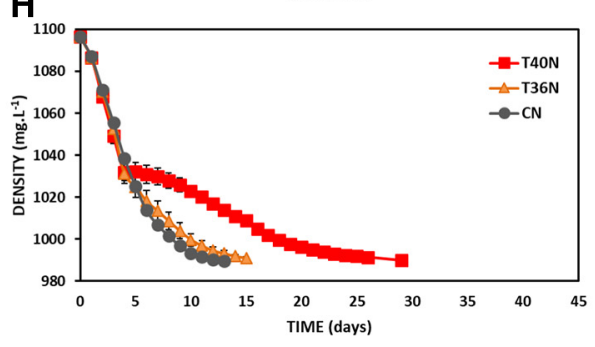

C

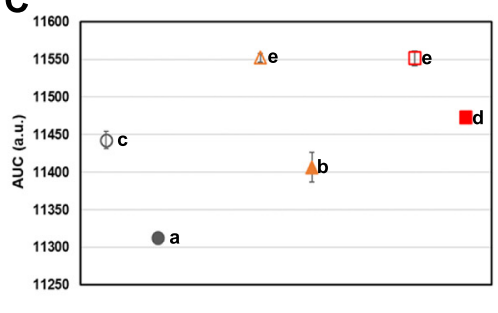

$\mathbf{F}$

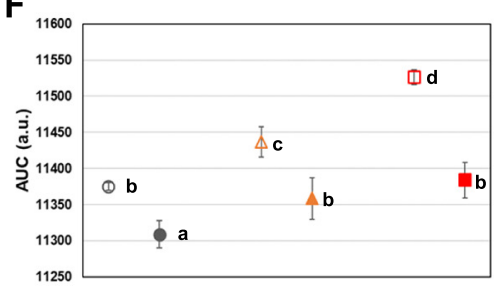

I

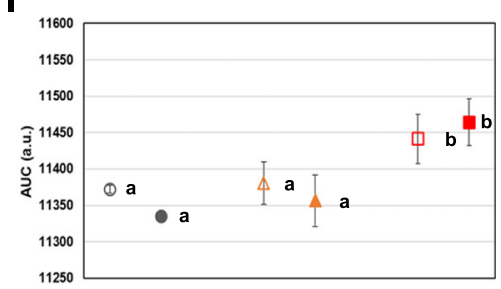

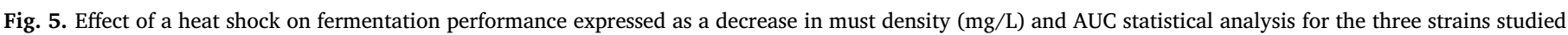

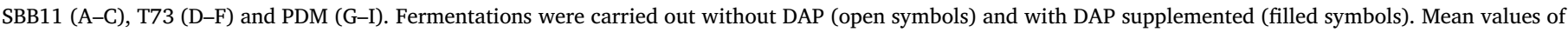

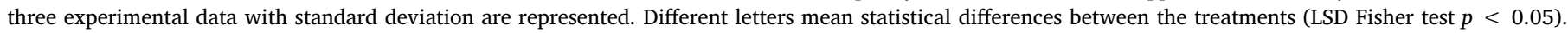

after the shock is shown as "vitality reduction". Reduction in yeast vitality was higher after a heat shock at $40^{\circ} \mathrm{C}$ compared to $36^{\circ} \mathrm{C}$ for all strains studied (Fig. 6). Vitality reduction directly correlated with the delay in fermentation performance observed in Fig. 5. However, DAP supplementation was not always able to protect cells immediately after the shocks, showing variable percentages of vitality reduction in the different conditions, depending on the strain and temperature of the shock (Fig. 6). For SBB11 and PDM, DAP supplementation before $36^{\circ} \mathrm{C}$ heat shock allowed a smaller vitality reduction compared to treatments without nutrition. In contrast, in $40^{\circ} \mathrm{C}$ heat shock assays, DAP supplemented treatments showed higher vitality reduction compared to treatments without DAP for those strains. T73 was the only strain where a positive effect of DAP supplementation on cell vitality was observed after a $40{ }^{\circ} \mathrm{C}$ heat shock (Fig. 6). The latter is in line with the previous observations regarding fermentation performance, where DAP supplementation produced a significant improvement on fermentation performance (Fig. 5D, E). Cell vitality was evaluated the day after the heat shock (day 4), and $96 \mathrm{~h}$ later (day 7) to determine cell vitality recovery (Fig. 7). In none of the heat shock treatments vitality was restored, since on day 7 vitality yeasts percentages remained similar to those observed

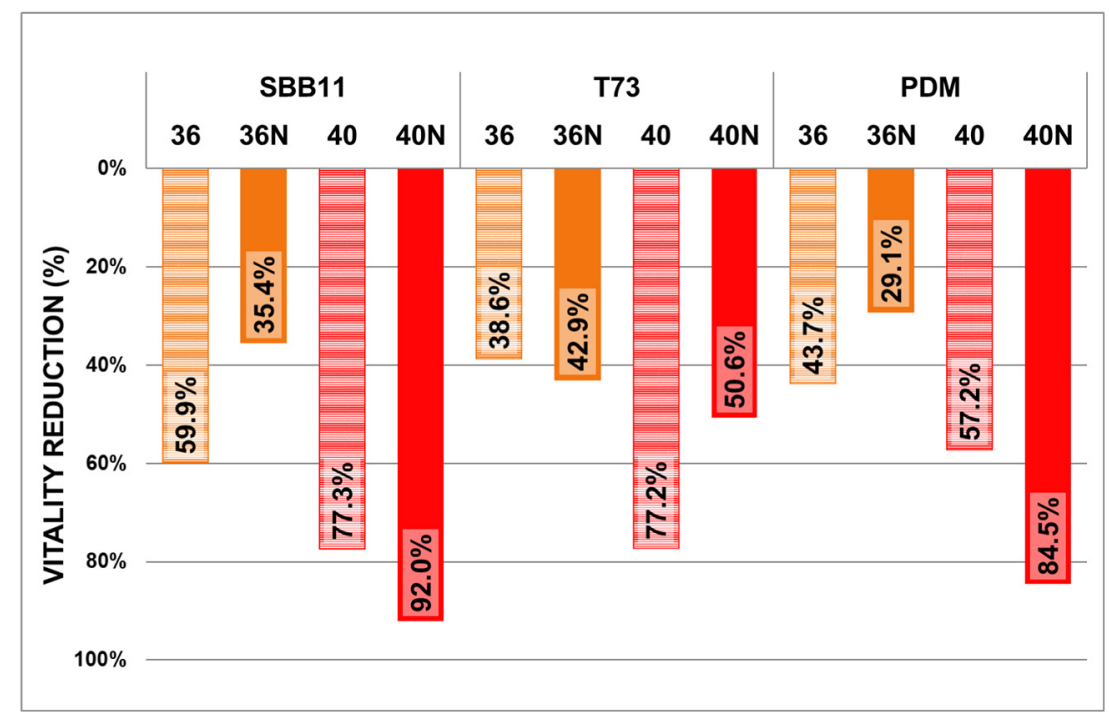

Fig. 6. Vitality reduction the day after the heat shock. Cellular vitality evaluated by flow cytometry in cells stained with CFDA for the three strains SBB11, T73 and PDM. Results are expressed as vitality reduction, calculated as detailed in Material and Methods section. 


\section{WITHOUT DAP}

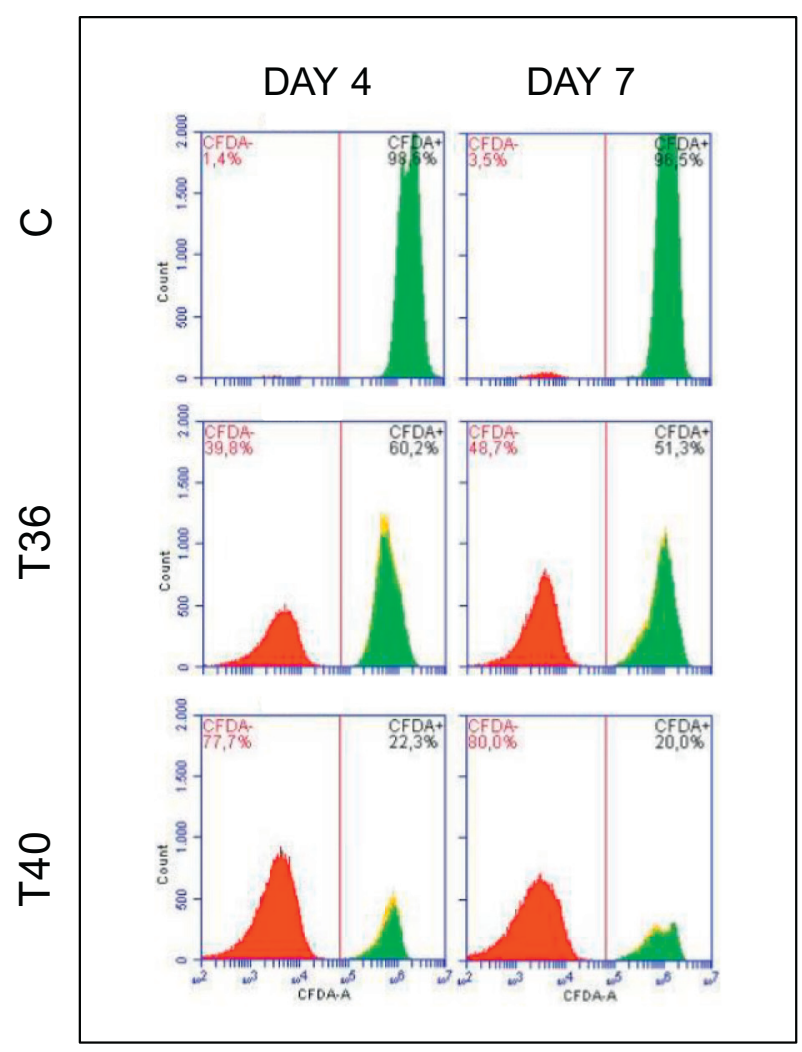

WITHDAP

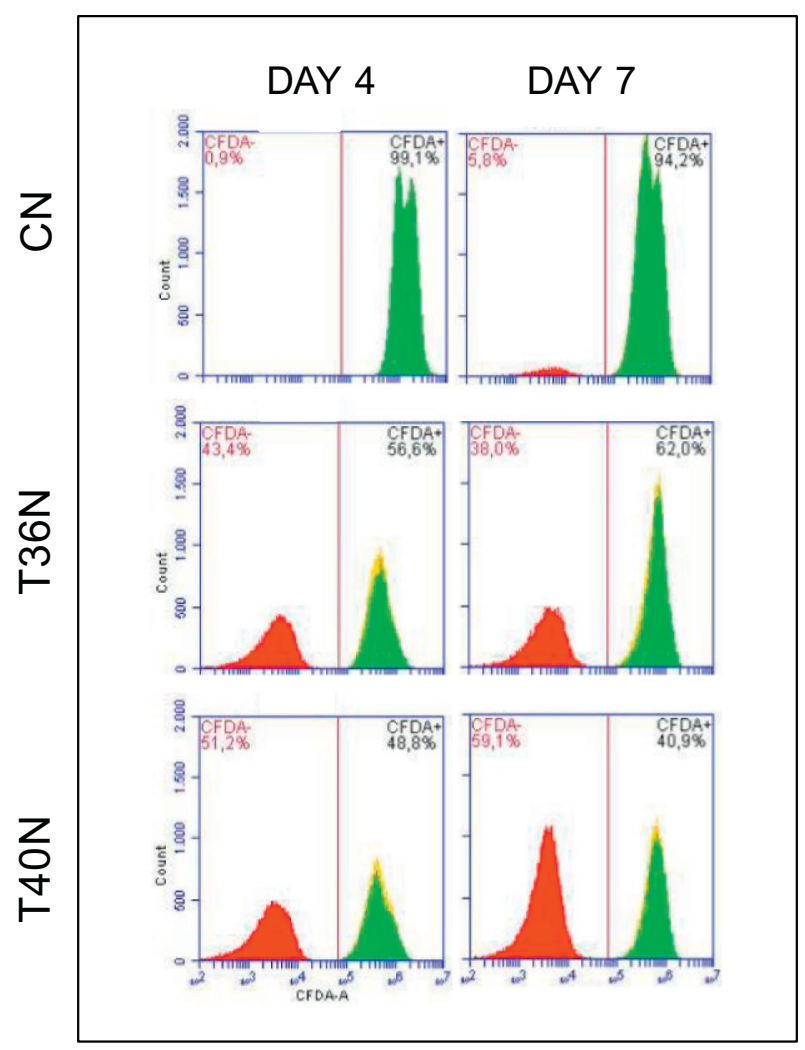

Fig. 7. Cell vitality on day 4 and day 7 measured with flow cytometry from treatments (control, $36{ }^{\circ} \mathrm{C}$ and $40{ }^{\circ} \mathrm{C}$ ) performed with the strain T73. Red: Non-vital cells (CFDA- PI+), Green: vital cells (CFDA + PI-) and Yellow: vital cells with compromised membranes (CFDA + PI +). Cells were gated based on viable and non-viable controls. DAP: diammonium phosphate. (For interpretation of the references to colour in this figure legend, the reader is referred to the web version of this article.)

on day 4 for all strains, as shown in Fig. 7 for T73. The observed decrease on yeast vitality was maintained throughout the whole process and was correlated with the observations on fermentative performance since fermentation rate is neither completely recovered after the shock.

\section{Discussion}

It is widely known that thermal changes can occur during alcoholic fermentation due to external factors such as environmental temperature or factors directly related to the fermentation process itself, such as yeast metabolic activity and nutrition. Despite many improvements in winemaking technology have been incorporated in order to maintain fermentation temperature in a security range, certain conditions exceed the capacity to control the temperature, mainly in large volume fermentations with high thermal inertia. Thermal changes as causes of sluggish or stuck fermentation have been barely studied. The main goal of this study was to identify transient thermal conditions leading to problematic fermentations.

Decreases in environmental temperature are highly frequent in nature and may take place seasonally, daily or just unexpectedly, depending on the region, climate and environment. Our experiment was designed in order to verify previous observations occurring in our experimental cellar, where stuck fermentations were recorded days after an abrupt decrease in environmental temperature. Cold shocks were carried out on different days during alcoholic fermentations characterized by increasing ethanol content. The results showed that even an abrupt and transient reduction to a temperature near $1.5^{\circ} \mathrm{C}$ applied in a high ethanol concentration did not affect alcoholic fermentation. In line with our results, Valentine et al. (2018) studied short-term temperature changes in one industrial wine yeast grown under conditions resembling winemaking, trying to reproduce cooling of a warm fermentation by a heat exchanger. A short cold shock from $34^{\circ} \mathrm{C}$ to $0{ }^{\circ} \mathrm{C}$ during $20 \mathrm{~s}$ showed no adverse effect on fermentation performance for up to $80 \mathrm{~h}$ after treatment (Valentine et al., 2018). Our results are consistent with the observations that a near-freezing temperature reduces cell metabolism (enzyme kinetics) and membrane fluidity, and cells enter in a quiescent state similar to starvation (Panadero et al., 2006; Price and Sowers, 2004). This later is evidenced by a temporal decrease in fermentation kinetics, which is immediately recovered after returning to a higher temperature. No synergistic effect of ethanol and cold shock on reducing the vitality of the yeast was evidenced.

As mentioned before, temperature increases are frequently recorded during alcoholic fermentation. During the first days of alcoholic fermentation, increases in must temperature reaches up to $39^{\circ} \mathrm{C}-40^{\circ} \mathrm{C}$ which risks the end of fermentation (Guerrini et al., 2017; Valentine et al., 2018). However, in red wine fermentations temperatures are not a homogenous mixture in terms of both density (grape solids and liquid) and temperature distribution (Schmid et al., 2009). The highest temperatures are registered in the cap and are dissipated to the liquid fraction after every pump-over procedure. As previously reported by Guerrini et al. (2017) temperature maximums are reached during overnights on the first three days of fermentation. The experimental 
design of our study aimed to reproduce these temperatures increases on must and its effect on fermentation performance and cell viability and vitality. Must nutrition during alcoholic fermentation is a widely used oenological practice. Consequently, DAP supplementation on day 3 was included as variable in our experimental design.

A heat shock at temperatures higher than $32{ }^{\circ} \mathrm{C}$ significantly affected fermentation performance and yeast viability/vitality, being the effect directly related with the temperature. The latter confirms that sudden and transient increases in must temperature are able to produce a sluggish fermentation, although no complete arrest was evidenced under the conditions assessed in this study. It was recently reported that cells briefly exposed during fermentation to higher temperatures than those applied in this study (i.e. up to $50{ }^{\circ} \mathrm{C}$ for $20 \mathrm{~s}$ ), showed no impact on culture viability or fermentation progress (Valentine et al., 2018). Importantly, heat shock length in the mentioned study is radically lower than that applied in our study ( $20 \mathrm{~s}$ vs. $16 \mathrm{~h}$ ), suggesting that the combination of temperature and length of the heat shock treatment determined the final effect on the fermentative process.

Despite most heat shock treatments produced an impact leading to sluggish fermentations, the magnitude of the effect on fermentation performance was strain and nutrition dependent. For instance, SBB11 showed to be the most sensitive strain to both heat shock temperatures. Although DAP supplementation produced a slight reduction in fermentation length, heat shock led to a clear sluggish in fermentation for this strain. In the case of $\mathrm{T} 73,36^{\circ} \mathrm{C}$ and $40^{\circ} \mathrm{C}$ heat shocks produced a strong effect on fermentation performance in absence of nutrition, which was practically reverted when DAP supplementation was carried out. The latter suggests that T73 is strongly favoured by nutrition. Finally, PDM fermentation performance was not negatively affected by heat shocks at $36^{\circ} \mathrm{C}$, being only altered when a $40{ }^{\circ} \mathrm{C}$ heat shock was applied. Also nutrition did not modify the immediate response of this strain, however total fermentation length was shorter when DAP was added. PDM seems to be the most thermotolerant strain assessed, since only heat shocks at the highest temperatures (i.e. $40^{\circ} \mathrm{C}$ ) were able to produce a sluggish fermentation. This latter is in line with previous studies that indicate that PDM presents fitness advantage over other $S$. cerevisiae strains, being able to ferment in a wider temperature range, showing tolerance to temperatures within the range of 40 to $45^{\circ} \mathrm{C}$ (García-Ríos et al., 2014). Regarding nutritional requirements, PDM has been described as a great nitrogen demander (Gutiérrez et al., 2012). However, in our experiments this was not evidenced in the AUC measurements until day 11 . Nonetheless, a clear decrease in fermentation length was observed in DAP supplemented fermentations. It is generally accepted that nitrogen addition produces an increase in biomass and stimulates the rate of sugar consumption (Beltran et al., 2005). In our study an improvement in the metabolic activity may support the recovery of the fermentation rate after heat shocks in DAP supplemented treatments, since no increment in biomass was evidenced.

Traditionally, heat treatments have been widely employed in food industry due to its lethal effect on spoiler or pathogen microorganisms. Heat injury of vegetative cells is multi targeted. The site of damage can be some cell wall components, the cytoplasmic membrane, ribosomes and ribosomal RNA, as well as degradation and misfolding of proteins (Smelt and Brul, 2014; Yamamoto et al., 2008). In our study, yeast viability loss followed by no recovery after $96 \mathrm{~h}$ of heat shock, showed to be the cause of the decrease in fermentation rate. In contrast, other authors have shown that a brief exposure (i.e. $20 \mathrm{~s}$ ) to high temperatures causes the temporary loss of population viability (Valentine et al., 2018). The authors reported that a delay in the reinitiation of fermentation depends on the restoration of cell number, followed by a complete recovery of fermentation rate. Additionally, cells exposed to a period of sublethal heat can initiate a separate set of mechanisms that improves heat tolerance (Jarolim et al., 2013; Valentine et al., 2018). In contrast, our results showed no viability recovery, suggesting that heat shocks assessed in our study had a combination of length and intensity that overpassed cell response capacity, therefore fermentation rate was never completely recovered. However, fermentations finished at a very low rate after the thermal shocks, suggesting the possible presence of a residual viable population less affected by the heat. In this sense, the conditions assessed in our study where temperature distribution was not homogeneous (i.e. heat shock in static conditions) would result in cells differently affected by the heat, leaving a fraction of viable cells able to complete the fermentative process.

Despite none of the heat treatments assessed produced stuck fermentation, it is important to highlight that sluggish fermentations as those observed in this study (taking 40-45 days) are a great struggle for winemakers, bringing huge operative and logistics problems to the industry. In all cases DAP supplementation improved the global performance after a heat shock, reducing fermentation lengths. This later suggest that nutrition would be a recommendable practice since it has shown a positive effect against heat shocks that may occur during the first days of fermentation. Consequently, an adequate management of fermentation temperature is highly recommended to avoid fermentative problems.

\section{Conclusions}

The purpose of this study was to evaluate thermal conditions able to produce problematic fermentations. Specifically, the effect of an abrupt and transient reduction or increase of must temperature on fermentation performance was evaluated. We evidenced that a cold shock is not able to alter the fermentation performance, even if produced in different moments of alcoholic fermentation. In contrast, heat shocks occurring during the first days of fermentation can lead to sluggish fermentations whose intensity is directly related to the temperature of the heat shock applied. Moreover, fermentation delay was attributable to decreased cell vitality. Three $S$. cerevisiae strains were studied and showed to be differently affected by the thermal shocks. Interestingly, DAP supplementation showed to confer a positive effect against heat shocks, since improvement in fermentation rate was observed for all treatments subjected to nutrition.

\section{Acknowledgements}

This work was supported by Consejo Nacional de Investigaciones Científicas y Técnicas (CONICET) through the projects: PIP 2014-2016 (Ref 11220130100694) (Argentina) and PCB NII CONICET-CSIC; Agencia Nacional de Promoción Científica y Tecnológica PICT 2016FONCyT 3406 (Argentina); Instituto Nacional de Tecnología Agropecuaria (INTA) PNAIyAV 1130032; and Consejo Superior de Investigaciones Científicas (CSIC) I-COOP B 20316 (Spain). A.S.V.T was awarded with a fellowship from Fundación Carolina in Tarragona, Spain. We are grateful to $\mathrm{PhD}$ Jorge Pérez-Peña for critical reading of this article and helpful suggestions.

\section{References}

Beltran, G., Esteve-Zarzoso, B., Rozès, N., Mas, A., Guillamón, J.M., 2005. Influence of the timing of nitrogen additions during synthetic grape must fermentations on fermentation kinetics and nitrogen consumption. J. Agric. Food Chem. 53, 996-1002. https://doi.org/10.1021/jf0487001.

Bely, M., Sablayrolles, J.M., Barre, P., 1990. Automatic detection of assimilable nitrogen deficiencies during alcoholic fermentation in oenological conditions. J. Ferment. Bioeng. 70, 246-252. https://doi.org/10.1016/0922-338X(90)90057-4.

Bisson, L.F., 1999. Stuck and sluggish fermentations. Am. J. Enol. Vitic. 50, 107-119.

Bisson, L.F., Karpel, J.E., Ramakrishnan, V., Joseph, L., 2007. Functional genomics of wine yeast Saccharomyces cerevisiae. Adv. Food Nutr. Res. 53, 65-121. https://doi org/10.1016/S1043-4526(07)53003-2.

Coulter, A.D., Henschke, P.A., Simos, C.A., Pretorius, I.S., 2008. When the heat is on, yeast fermentation runs out of puff. Aust. N.Z. Wine Ind. 23, 26-30.

García-Ríos, E., Gutiérrez, A., Salvadó, Z., Arroyo-López, F.N., Guillamon, J.M., 2014. The fitness advantage of commercial wine yeasts in relation to the nitrogen concentration, temperature, and ethanol content under microvinification conditions. Appl. Environ. Microbiol. 80, 704-713. https://doi.org/10.1128/AEM.03405-13.

Guerrini, L., Angeloni, G., Baldi, F., Parenti, A., 2017. Thermal effects of pump-overs during red wine fermentation. Appl. Therm. Eng. 112, 621-626. https://doi.org/10. 
1016/j.applthermaleng.2016.10.155.

Gutiérrez, A., Chiva, R., Sancho, M., Beltran, G., Arroyo-López, F.N., Guillamon, J.M., 2012. Nitrogen requirements of commercial wine yeast strains during fermentation of a synthetic grape must. Food Microbiol. 31, 25-32. https://doi.org/10.1016/j.fm. 2012.02.012.

Ivorra, C., Pérez-Ortín, J.E., del Olmo, M., 1999. An inverse correlation between stress resistance and stuck fermentations in wine yeasts. Biotechnol. Bioeng. 64, 698-708.

Jarolim, S., Ayer, A., Pillay, B., Gee, A.C., Phrakaysone, A., Perrone, G.G., Breitenbach, M., Dawes, I.W., 2013. Saccharomyces cerevisiae genes involved in survival of heat shock. G3 (Bethesda) 3, 2321-2333. https://doi.org/10.1534/g3.113.007971.

Lonvaud-Funel, A., 1999. Lactic acid bacteria in the quality improvement and depreciation of wine. Anton Leeuw. Int. J. G. 76, 317-331.

Maisonnave, P., Sanchez, I., Moine, V., Dequin, S., Galeote, V., 2013. Stuck fermentation: development of a synthetic stuck wine and study of a restart procedure. Int. J. Food Microbiol. 163, 239-247. https://doi.org/10.1016/j.ijfoodmicro.2013.03.004.

Malherbe, S., Bauer, F.F., Du Toit, M., 2007. Understanding problem fermentations - a review. S. Afr. J. Enol. 28, 169-186. https://doi.org/10.21548/28-2-1471.

Panadero, J., Pallotti, C., Rodríguez-Vargas, S., Randez-Gil, F., Prieto, J.A., 2006. A downshift in temperature activates the high osmolarity glycerol (HOG) pathway, which determines freeze tolerance in Saccharomyces cerevisiae. J. Biol. Chem. 281, 4638-4645. https://doi.org/10.1074/jbc.M512736200.

Price, P.B., Sowers, T., 2004. Temperature dependence of metabolic rates for microbial growth, maintenance, and survival. Proc. Natl. Acad. Sci. U. S. A. 101, 4631-4636. https://doi.org/10.1073/pnas.0400522101.
Ribereau-Gayon, P., Dubordieu, D., Doneche, B., Lonvaud, A., 2006. Handbook of Enology: The Microbiology of Wine and Vinifications. 1 John Wiley and Sons Ltd, New York, USA.

Samuel, D., 1996. Investigation of ancient Egyptian baking and brewing methods by correlative microscopy. Science 273, 488-490.

Schmid, F., Schadt, J., Jiranek, V., Block, D.E., 2009. Formation of temperature gradients in large- and small-scale red wine fermentations during cap management. Aust. J. Grape Wine R. 15, 249-255. https://doi.org/10.1111/j.1755-0238.2009.00053.x.

Smelt, J.P., Brul, S., 2014. Thermal inactivation of microorganisms. Crit. Rev. Food Sci. Nutr. 54, 1371-1385. https://doi.org/10.1080/10408398.2011.637645.

Tonietto, J., Carbonneau, A., 2004. A multicriteria climatic classification system for grape-growing regions worldwide. Agric. For. Meteorol. 124, 81-97. https://doi.org/ 10.1016/j.agrformet.2003.06.001.

Urtubia, A., Hernández, G., Roger, J.M., 2012. Detection of abnormal fermentations in wine process by multivariate statistics and pattern recognition techniques. J. Biotechnol. 159, 336-341. https://doi.org/10.1016/j.jbiotec.2011.09.031.

Valentine, G.D.S., Walker, M.E., Gardner, J.M., Schmid, F., Jiranek, V., 2018. Brief temperature extremes during wine fermentation: effect on yeast viability and fermentation progress. Aust. J. Grape Wine R. 25, 62-69. https://doi.org/10.1111/ ajgw.12365.

Yamamoto, N., Maeda, Y., Ikeda, A., Sakurai, H., 2008. Regulation of thermotolerance by stress-induced transcription factors in Saccharomyces cerevisiae. Eukaryot. Cell 7, 783-790. https://doi.org/10.1128/EC.00029-08. 